\title{
Explorando a Evolução do Problema de Pesquisa de Doutorado: Um Estudo Qualitativo no LER/UFPE
}

\author{
Enyo Gonçalves ${ }^{1,2}$, Ana Carla Holanda ${ }^{1,3}$, Dorgival Netto ${ }^{1}$, Helena Cristina \\ Bastos $^{1}$, André Calisto ${ }^{1}$, Mayara Santos ${ }^{1}$, Fabio Q. B. Silva ${ }^{1}$, Carla Silva ${ }^{1}$, Jaelson \\ Castro ${ }^{1}$ \\ ${ }^{1}$ Centro de Informática - Universidade Federal de Pernambuco, Recife-PE, Brasil \\ ${ }^{2}$ Universidade Federal do Ceará, Campus Quixadá \\ ${ }^{3}$ Instituto Federal de Educação Ciência e Tecnologia do Acre \\ \{ejtg, acah, dpsn2, hcab2, acsmg, mwas, fabio, ctlls, jbc\}@cin.ufpe.br
}

\begin{abstract}
Resumo. Neste artigo, vamos explorar como evoluem os problemas de pesquisa de doutorado, mais especificamente, no grupo de pesquisa LER (Laboratório de Engenharia de Requisitos) da Universidade Federal de Pernambuco (UFPE). Para tanto, foi realizado um estudo qualitativo para identificar fatores que podem influenciar na evolução do problema de pesquisa dos alunos de doutorado. Entrevistas semiestruturadas foram realizadas e dados foram coletados com o objetivo de termos subsídios para responder às questões de pesquisa. Os resultados indicam que existem fatores que se relacionam e que juntos podem facilitar a evolução do problema de pesquisa do doutorado. Por exemplo, o conhecimento prévio do aluno que, mesmo não sendo determinante, auxilia nessa evolução. Além disso, a definição do tema pode ser influenciada por um acompanhamento sistemático das atividades do aluno, pode influenciar positivamente no fator psicológico do orientando. A participação em workshops de teses e dissertações em computação e a interação com a indústria também podem influenciar de forma positiva.
\end{abstract}

\section{Introdução}

Segundo dados do Ministério da Educação (MEC), o Brasil conta atualmente com 10.161 discentes matriculados em cursos de doutorado na área de ciências exata e da terra, sendo que cerca de 1.600 são da área de computação [GEOCAPES, 2015]. Um fato comum, no contexto de doutorado em computação no Brasil, se refere a pedidos de prorrogação de prazo da defesa da tese. Este pode ser um indicador de que há dificuldade na evolução dos problemas de pesquisa de doutorado nesta área.

É importante entender como evoluem os problemas de pesquisa de doutorado na área de computação e os fatores que os influenciam. Esse entendimento pode contribuir para uma melhor condução da pesquisa do doutorado em computação por parte dos discentes, além de possibilitar que aspectos que influenciem negativamente na evolução do seu problema de pesquisa sejam identificados.

Assim sendo, um estudo qualitativo pode contribuir na identificação de fatores que estão relacionados e influenciam diretamente ou indiretamente na evolução do problema. Este artigo apresenta os resultados de um estudo qualitativo realizado junto 
ao Laboratório de Engenharia de Requisitos (LER) do Programa de Pós-Graduação em Ciência da Computação da Universidade Federal de Pernambuco (UFPE).

A contribuição deste trabalho se concentra na educação em informática em nível de pós-graduação. Os resultados deste trabalho podem ajudar alunos e orientadores de programas de doutorado a entender melhor como evoluem os problemas de pesquisa por meio de fatores que podem influenciar na evolução.

O restante do artigo está organizado como segue. A Seção 2 apresenta o referencial teórico e a Seção 3 os trabalhos relacionados. A Seção 4 caracteriza a metodologia seguida no desenvolvimento deste trabalho. Na Seção 5 são apresentados os resultados e discussões. E por fim, na Seção 6 são apresentadas as conclusões.

\section{Referencial Teórico}

Uma tese de doutorado pode trazer muitos benefícios para a vida acadêmica e profissional para o discente de uma Pós-Graduação strictu sensu. Neste sentido, muitas são as motivações para um candidato almejar essa conquista.

Porém, sabe-se que se trata de uma missão demorada, complexa e árdua, onde há muita "transpiração" como também inspiração [Duque, Brondani e Luna, 2005]. A Inteligência Emocional [Goleman, 1996] é um fator que merece ser destacado. O conceito de Inteligência Emocional surgiu no âmbito acadêmico, em 1990, formalizado pelos pesquisadores Peter Salovey (Yale University) e John Mayer (University of New Hampshire). Neta, García e Gargallo [2008] definem inteligência emocional como sendo a habilidade para controlar os sentimentos e emoções em si mesmo e nos demais, discriminar entre elas e usar essa informação para guiar as ações e os pensamentos.

Assim, Neta, García e Gargallo [2008] consideram a evolução de um mestrado ou doutorado como a realização de um projeto, este sendo definido como um esforço temporário empreendido para criar um produto, serviço ou resultado exclusivo. Os autores apresentam uma lista de verificação e riscos que podem surgir no decorrer do doutorado e propõem boas práticas no desenvolvimento de teses e dissertações.

Estes autores também procuraram identificar e avaliar possíveis fatores desencadeantes de estresse em pós-graduandos de diferentes áreas. Observam durante a pesquisa que a pressão por publicar leva a um grau exagerado de competitividade, induzindo uma distorção cultural, na qual a "corrida por produção" prevalece sobre o conhecimento.

\section{Trabalhos Relacionados}

O trabalho de Godoy, Silva e Figueiredo [2011] procura analisar o impacto de uma proposta de incorporação de prática docente e formação pedagógica aos cursos de pós-graduação na Unicamp - o Programa de Estágio Docente (PED). Os autores visam avaliar diferentes fatores relacionados à confiança na prática de pesquisa e ensino do mestrando e do doutorando em Engenharia Elétrica e em Ciência da Computação. O método utilizado envolveu a aplicação de um questionário autoaplicado para melhor entendimento da confiança. Nosso trabalho, assim como este, também está relacionado ao entendimento de fenômenos da pós-graduação em computação, porém nos concentramos no entendimento de como evoluem os problemas de pesquisa de doutorado. 
Em Stump et al. [2011], os autores abordam a necessidade de se proporcionar formação em Cognição e Aplicações Computacionais aos alunos de pós-graduação stricto sensu em Computação. As estruturas conceituais e práticas relativas aos processos cognitivos foram abordadas. Também é apresentada uma forma de aperfeiçoamento da capacidade de construir um conhecimento organizado, por meio de uma proposta curricular para cursos stricto sensu na área da Computação e correlatas. $\mathrm{O}$ trabalho de Stump et al. [2011] assim como o nosso foca na melhoria da pós-graduação por meio do suporte a cognição dos alunos, no entanto o trabalho deste autores se concentra na defesa da criação de uma disciplina para tal finalidade.

Segundo Silvetti et al. [2013], participar de um Doutorado Sanduíche ou de uma colaboração internacional é uma experiência enriquecedora, profissional e pessoalmente. Esta experiência permite que alunos de pós-graduação conheçam outros grupos de pesquisa, experimentem diferentes processos de trabalho acadêmico, aprendam formas alternativas de financiamento de pesquisa, além de estreitar contatos e criar parcerias com pesquisadores em diferentes países. O trabalho de Silvetti et al.[2013] dá ênfase a somente um dos fatores que identificamos neste artigo.

\section{Metodologia}

[Problema de Pesquisa] O propósito deste trabalho é contribuir para um melhor entendimento de como evoluem os problemas de pesquisa de doutorado em computação. [Design do estudo] Nós utilizamos uma abordagem de pesquisa qualitativa básica realizada no grupo de pesquisa LER, o qual foi escolhido de forma intencional, por se tratar de um grupo de pesquisa consolidado no centro de informática da UFPE. [Amostra dos participantes] A unidade de análise do estudo é composta pelos alunos do grupo LER que se encaixem no seguinte intervalo: dois anos ou mais de ingresso no doutorado e menos de seis meses após a defesa. Os respectivos orientadores dos alunos entrevistados também foram considerados como participantes da pesquisa, como forma de realizar uma triangulação das informações. O propósito de utilizar uma amostra não probabilística encontra-se na seleção da informação, pois é possível escolher casos ricos para o estudo realizado [Merriam, 2009].

[Preparação da Coleta] Entrevistas semiestruturadas foram realizadas utilizando roteiros de entrevista especificamente concebidos e compostos de perguntas abertas. Os roteiros de entrevista foram pré-testados, através de uma entrevista piloto com um dos alunos de doutorado que é membro do LER e que estava no intervalo da amostra. Esta experiência ajudou a refinar os roteiros de entrevista (ver Quadro 1 e Quadro 2). Após a realização das entrevistas, ocorreu a transcrição e codificação e categorização dos dados. Também realizamos entrevistas de retrospectiva para clarificar e complementar as informações identificadas na análise dos dados. [Coleta de Dados] As entrevistas foram realizadas presencialmente nas instalações do centro de informática da UFPE (Com exceção de uma das entrevistas que foi realizada remotamente via skype), nos meses de outubro e novembro 2015. Oito participantes foram entrevistados: cinco alunos (dos quais dois já haviam concluído o curso) e três orientadores. Todas as entrevistas foram gravadas (com autorização prévia do entrevistado) e juntas totalizam 5 horas e 20 minutos de tempo de áudio. [Análise de Dados e Síntese] Seguimos diretrizes fornecidas por Strauss e Corbin [2007] para categorizar e sintetizar dados, com o objetivo de construir uma teoria baseada em 
evidências como evolui o problema de doutorado em computação. $\mathrm{O}$ áudio das entrevistas foi transcrito e QSR NVIVO 11 foi usado para apoiar o processo de análise. Nós consideramos porções rotuladas de texto usando códigos (Iniciamos com codificação aberta, depois fizemos codificação fechada e por fim foi utilizada a codificação axial) e em seguida estes códigos foram relacionados dando origem às categorias que foram nomeadas seguindo um método de comparação constante [Strauss e Corbin, 20070]. Em seguida, as relações entre categorias foram mapeadas, levando a proposições que sustentam a estória central.

[Credibilidade, Consistência e Transferência dos Resultados] Nós utilizamos triangulação para aumentar a credibilidade dos dados. Além disto, os dados foram discutidos em grupo durante reuniões e inconsistências identificadas foram tratadas tanto nas discussões quanto em explicações complementares dos participantes.

\section{Quadro 1. Roteiro de Entrevista dos Alunos}

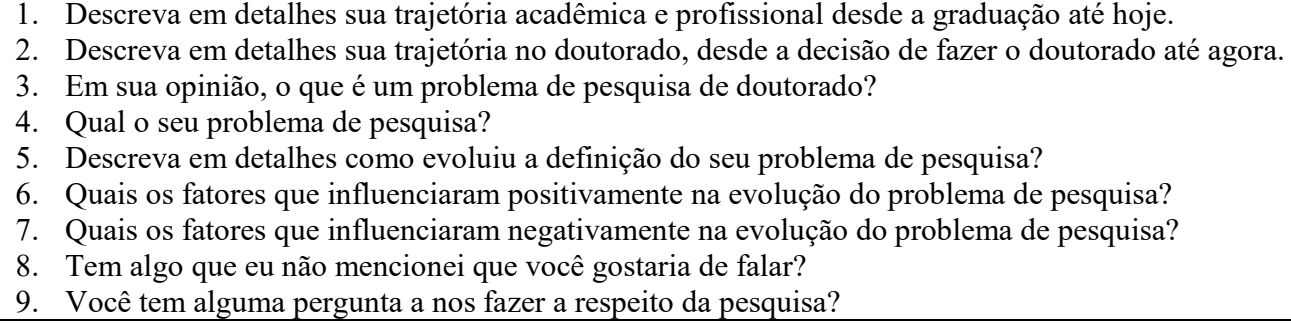

1. Descreva em detalhes sua trajetória acadêmica e profissional desde a graduação até hoje.

2. Descreva em detalhes sua trajetória no doutorado, desde a decisão de fazer o doutorado até agora.

3. Em sua opinião, o que é um problema de pesquisa de doutorado?

4. Qual o seu problema de pesquisa?

5. Descreva em detalhes como evoluiu a definição do seu problema de pesquisa?

6. Quais os fatores que influenciaram positivamente na evolução do problema de pesquisa?

7. Quais os fatores que influenciaram negativamente na evolução do problema de pesquisa?

8. Tem algo que eu não mencionei que você gostaria de falar?

9. Você tem alguma pergunta a nos fazer a respeito da pesquisa?

\section{Quadro 2. Roteiro de Entrevista dos Orientadores}

1.Em sua opinião, o que é um problema de pesquisa para o doutorado?

2.Como um problema de pesquisa é definido?

3.Quais os fatores que influenciam positivamente a definição de um problema de pesquisa?

4.Quais os fatores que influenciam negativamente a definição de um problema de pesquisa?

5.Cite um exemplo de um orientado que você considera o ideal e que não teve dificuldade para definir o problema de pesquisa e no terminou no tempo ideal.

6.Cite um exemplo de um orientado que você considera o mais difícil, que teve dificuldade para definir o problema de pesquisa e não terminou no tempo ideal.

7.Você aplica algum método específico para ajudar seus orientandos a definir o problema de pesquisa deles?

8.Tem algo que eu não mencionei que você gostaria de falar?

9.Você tem alguma pergunta a nos fazer a respeito da pesquisa?

\section{RESULTADOS E DISCUSSÃO}

Nós realizamos uma investigação qualitativa para descobrir quais possíveis fatores podem facilitar positivamente e negativamente a evolução do problema e os dados estão apresentados nas subseções seguintes.

\subsection{Descrição do Contexto}

Desde 1997, o grupo LER visa estabelecer bases para aumentar a qualidade do processo de produção de software por meio da cooperação com universidades e empresas e focando em atividades Engenharia de Requisitos. O foco de pesquisa do grupo trata-se de Engenharia de Requisitos, uma das fases mais críticas do ciclo de desenvolvimento de software. Exige que os clientes pensem sobre suas necessidades com cuidado e o objetivo da fase de Engenharia de Requisitos é produzir uma especificação completa sobre o software para resolver o problema do cliente. $O$ grupo possui 15 teses de doutorado defendidas e 134 dissertações concluídas. 


\subsection{Como os indivíduos entendem um problema de doutorado e a evolução do problema}

Antes de cada entrevista começar foi dada uma explicação sobre o propósito da pesquisa e solicitada concordância dos entrevistados para realização da gravação. Inicialmente abordamos o entendimento dos entrevistados sobre o que é um problema de doutorado e como este problema evolui. No roteiro de entrevista dos alunos temos três perguntas relacionadas a este tema (Q3, Q4 e Q5 - Quadro 1) e no roteiro dos orientadores temos duas perguntas (Q1 e Q2 - Quadro 2).

Não encontramos uma definição clara na literatura para problema de pesquisa de doutorado, nem uma diferenciação do que seria um problema adequado. Assim sendo, é compreensível que doutorandos ou mesmo recém-doutores tenham dificuldade de responder a este questionamento. Nos discursos de dois alunos participantes podemos ter esta constatação:

— “O que é um problema de pesquisa... [Longo momento de pausa] Descobrir... É ... às vezes tem um problema já existente na indústria ou na academia e outra coisa é encontrar um problema." (Entrevistado 3)

— "Um problema de pesquisa é uma lacuna que ficou de pesquisas anteriores ou um problema novo que você decide investigar." (Entrevistado 4)

Vale a pena destacar no discurso do Entrevistado 3 o fato de ter mencionado esta questão de problemas na indústria. Este olhar para a indústria é uma característica cada vez presente nas pesquisas de computação, seja de modo a embasar/entender um fenômeno ou validar uma técnica proposta.

Um dos alunos entrevistados conseguiu conceituar problema de pesquisa de doutorado de forma consistente aos conceitos dados pelos orientadores entrevistados.

- "Um problema de doutorado tem que ser relevante, um problema real e que tenha uma solução original. Não tem que ser totalmente construído do zero, pois pode partir de uma pesquisa já realizada." (Entrevistado 6)

Vejamos discursos de alguns orientadores entrevistados.

— "É um problema que a gente consegue ter evidências de que existe e consegue mensurar sua relevância com base em referências. E ainda tem outra questão, que é a originalidade, que é outra dificuldade. Tem que mostrar que é algo que ninguém propôs ou mostrar que a sua solução é melhor." (Entrevistado 7)

Um dos professores foi além da definição dada pelos demais (do problema de definição geral, único e relevante) e destacou que muitos programas de alto nível pelo mundo aceitam um problema de doutorado se o aluno consegue publicar em conferências consolidadas:

— "Seu doutorado é doutorado se você publicar um paper em certos lugares, inclusive vários programas são assim... Se você tiver três papers, você não precisa escrever tese, são três papers e pronto. Vários programas de alto nível são assim.” (Entrevistado 8)

A pergunta seguinte diz respeito à descrição do problema de pesquisa por parte dos alunos. Cada um conseguiu descrever de forma clara e precisa seu problema de pesquisa, sendo que dois dos entrevistados ainda encontram-se no processo de evolução do problema, uma vez que estão com um pouco mais de dois anos de doutorado. 


\subsection{Categorias Centrais da Evolução do Problema de Doutorado}

Depois de analisar o entendimento dos participantes em relação ao conceito de problema de doutorado, o próximo passo foi identificar os fatores que afetam positivamente e negativamente a evolução do problema de pesquisa. Nesta subseção os códigos foram agrupados em fatores que influenciam a evolução do problema de pesquisa. Foram usados trechos de entrevistas com evidências relacionadas a cada categoria. A seguir apresentaremos as três categorias centrais.

1) O Conhecimento Prévio do aluno representa uma categoria central dentro do problema de pesquisa se relacionando com algumas categorias tais como: estágio, publicações no mestrado e continuidade na área e com o mesmo orientador, iniciação científica, intercâmbio, monitoria, conhecer a área de pesquisa na graduação. A colaboração com grupo no exterior faz parte do background, pois a realização de intercâmbio durante a graduação ou mestrado é uma das formas consideradas de realizar esta colaboração. Alguns trechos apresentados a seguir estão relacionados ao conhecimento prévio.

— "Além de assistir aula eu fiz um monte de atividades. Participei da empresa júnior daqui.... Ai depois, quando tava já perto de sair da empresa jr eu entrei no PET aqui do CIN, né... Nos últimos três semestres (graduação) aí, foi que comecei a entrar na área de requisitos... Estagiei no CESAR, trabalhando com TV digital." (Entrevistado 3)

- "No doutorado eu continuei com o tema. Isso permitiu o que? Que eu tivesse resultados no início do doutorado. Então não tinha que passar um tempão procurando..." (Entrevistado 4).

Publicar artigos científicos é muito importante para os programas de pósgraduação, para os orientadores e principalmente para os estudantes. A publicação é uma oportunidade de receber um feedback da comunidade acadêmica sobre seu trabalho. Esta categoria pode ser constatada nos trechos transcritos abaixo.

— "Peguei um probleminha e uma publicação e depois outro probleminha e outra publicação e assim foi. Até encontrar um problema maior que desse conta de ser o meu trabalho de doutorado." (Entrevistado 3)

— “...outra coisa é você ter publicações que demonstrem a evolução do seu tema. Quando conseguir definir seu problema de doutorado, manda logo para um fórum de doutorado, só para avaliar. À medida que você vai evoluindo é interessante que tenham esses marcos representados por artigos que você submeteu, ajuda a você a se alto regular, você tá cumprindo prazo e tendo feedback, você vai construindo..." (Entrevistado 7).

Uma característica bem interessante da área de computação é a existência de workshops de teses e dissertações, como mencionado pelo Entrevistado 7. Estes são importantes veículos para se obter um feedback de pesquisadores experientes da área quanto a relevância do problema a ser atacado.

2) O Acompanhamento Sistemático dos Resultados é alcançado por meio de pontos de checagem como os seminários realizados semestralmente pelo grupo LER, a qualificação, reuniões periódicas com o orientador ou co-orientador e por publicações (publicações no doutorado), o que permite uma orientação mais objetiva e focada em resultados concretos e incrementais. A experiência do orientador pode fazer com que ele 
consiga direcionar melhor o aluno durante os acompanhamentos, tendo impacto na evolução por meio do acompanhamento sistemático dos resultados. O doutorado sanduiche (intercâmbio) pode contribuir com o acompanhamento dos resultados, pois envolve um coorientador, o que e é um fato capaz de aumentar a cobrança e o feedback.

Vale ressaltar ainda que participar de grupo de pesquisa é sinônimo de ter contato mais próximo com diversos professores e alunos, permitindo um maior acompanhamento da pesquisa. Quanto mais o aluno tem debates sobre seu tema, mais ele estimula a visão crítica e a capacidade de argumentar e defender ideias, que são fundamentais para o desenvolvimento da pesquisa. Recortes das entrevistas evidenciam o impacto do acompanhamento sistemático como fator na evolução do problema:

- "Participar de grupos de pesquisa é muito importante. Um doutorado sanduíche é interessante desde que seja em um lugar que se trabalhe no contexto de sua pesquisa. Realizar publicações e fazer a qualificação o mais cedo possível é muito importante para receber feedback e fazer os ajustes necessários." (Entrevistado 6).

— "O mais interessante foi que eu pude fazer um intercâmbio, e foi ai que eu pude explorar vários pontos de computação autonômica. Ai quando eu voltei para o CIN tinha mais teoria, conhecia mais trabalhos... Fiquei mais focado. No final do doutorado eu fui para Trento que o pessoal era especialista nisso, tem projetos nesta área... E lá eles me direcionaram bastante no meu problema". (Entrevistado 3)

Este acompanhamento sistemático aumenta a pressão por resultados que o aluno deve apresentar. O estresse gerado por essa cobrança exige uma maturidade emocional do aluno, percebe-se uma relação entre as categorias Acompanhamento Sistemático de Resultados e Maturidade Emocional, uma influenciando diretamente a outra.

3) Maturidade Emocional foi um fator identificado nas transcrições como sendo relacionado a inteligência emocional e também bastante relacionado a capacidade de reagir com equilíbrio diante de fatores externos como nascimento de filho, ir trabalhar em outra cidade, perder emprego, perder um parente, separação. A Dedicação, Autonomia e Iniciativa foram identificadas nos discursos e por se tratarem de aspectos subjetivos individuais também podem ser categorizados como Maturidade Emocional e tem uma influência positiva. A Flexibilidade em relação ao problema de pesquisa foi mencionada como um fator positivo relacionado a maturidade do aluno.

Não há um consenso entre os entrevistados em relação à influencia da dedicação, como pode ser verificado nos trechos abaixo.

- "Ao mesmo tempo estava como professora em outra cidade e não conseguia me dedicar bem ao Doutorado." (Entrevistado 2).

- "Tudo depende do perfil do aluno, tem aluno que funciona melhor trabalhando e estudando. Depende do aluno é muito da personalidade da pessoa, isso dai de ser dedicação exclusiva é do aluno. O aluno tem que ver com o orientador"(Entrevistado 7).

— "Ai eu acho que fator número um é dedicação, se o cara não se dedicar o mínimo que são 40 por semana no doutorado por 4 anos, é impossível fazer.... eu acho que o número um é dedicação" (Entrevistado 8).

A autonomia e iniciativa do aluno também são fatores determinantes para a evolução do problema de pesquisa. Os trechos a seguir corroboram com essa afirmação. 
— "eu decidi que eu queria trabalhar com elicitação de requisitos então, foi quando eu propus para o meu orientador que queria trabalhar com elicitação" (Entrevistado 1).

— "o aluno tem que ter maturidade para não se perder em meio as muitas opiniões." (Entrevistado 7).

A Maturidade Emocional é um fator que influencia positivamente na evolução do problema de pesquisa durante o Doutorado. Quando o aluno é instável emocionalmente, o resultado para a evolução do problema de pesquisa é muito negativo.

\subsection{Construindo uma História Central}

As ideias apresentadas nas subseções anteriores foram relacionadas de forma a construir a história central que apresenta como evoluem os problemas de doutorado no LER e os fatores relacionados.

A evolução dos trabalhos de doutorado ocorre de formas bastante distintas no LER. Um dos entrevistados caracteriza a forma como seu problema de doutorado evoluiu como sendo uma abordagem incremental, na qual um pequeno problema foi encontrado e resolvido resultando em uma publicação e, posteriormente, problemas relacionados a este primeiro foram sendo acoplados, resolvidos e publicados até ter o resultado final que foi a tese. Outros dois alunos citam a evolução de forma um pouco diferente deste primeiro, onde o problema foi definido em um determinado momento, sendo um deles no início do doutorado e outro no decorrer dele, e que este problema foi sendo resolvido ao longo do doutorado. Já os dois alunos restantes tiveram dificuldade com a definição do problema de pesquisa, por isso, mudaram de tema e de orientação.

Dependendo do perfil do aluno, haver uma flexibilidade em relação ao problema pode ser algo extremamente positivo, uma vez que alunos flexíveis tem a possibilidade de abandonar problemas inviáveis ou que não são relevantes para uma pesquisa de doutorado. Ter equilíbrio emocional, para saber lidar com os momentos de alta produtividade e com os de desestímulo, pode ser um diferencial que juntamente com a postura pró-ativa podem compensar a ausência de conhecimento prévio do aluno e fatores externos que atrapalhem. Os fatores externos como problemas pessoais, nascimento de filho, ir trabalhar em outra cidade e problemas de saúde na família, podem atrapalhar a evolução do problema de pesquisa, uma vez que tem influência direta sobre o fator psicológico e a inteligência emocional.

A motivação do aluno com relação ao trabalho de pesquisa que está sendo realizado é fator determinante para o sucesso da pesquisa, pois junto a maturidade emocional o aluno saberá superar essas adversidades de forma equilibrada. $\mathrm{O}$ fato de computação ser uma ciência relativamente nova, onde novas linhas de pesquisa são fomentadas constantemente, também pode influenciar na evolução.

Outro aspecto importante é o acompanhamento sistemático dos resultados do aluno representado por meio de publicações no doutorado e pontos de checagem. A participação em workshops de teses e dissertações pode ser bastante útil no momento de definição do problema de pesquisa. A influência do orientador é determinante neste aspecto uma vez que sua experiência, pode levá-lo a identificar se o problema que está sendo definido pode ter desdobramentos para um doutorado e fazer sugestões de alterações/mudança no problema. A realização de doutorado sanduíche (Colaboração com grupo no exterior) foi citada tanto de forma positiva quanto de forma negativa. 
Foram mencionados vários benefícios para a evolução do problema de pesquisa como o acompanhamento do co-orientador do país de destino e contato com alunos de outros grupos. No entanto, a questão da adaptação foi identificada como tendo uma influência negativo associada a este fator. Apesar disto, o saldo é extremamente positivo. $\mathrm{O}$ período de colaboração com um grupo de pesquisa no exterior foi realizado na graduação ou no mestrado, chamado por alguns entrevistados de intercâmbio, contribui para o conhecimento prévio do aluno, que também é um dos fatores que influenciam na definição do problema de doutorado. Quando é realizado na forma de doutorado sanduíche, propicia o acompanhamento de um co-orientador, bem como o foco passa a ser a publicação de artigos. Além disso, ajuda na validação do problema de pesquisa.

Há um entendimento de que atividades realizadas na graduação como iniciação científica, atividades de extensão, estágio, monitoria, colaboração com grupo no exterior e a forma como o mestrado do aluno aconteceu (se houveram publicações no mestrado, por exemplo), podem fazer com que o aluno chegue ao doutorado com um melhor amadurecimento em pesquisa. Do mesmo modo, a continuidade na área de pesquisa e com o mesmo orientador podem influenciar positivamente, uma vez que o aluno consegue iniciar o doutorado com uma fase de adaptação mais branda. As disciplinas de metodologias de pesquisa são fundamentais para a evolução do problema de pesquisa. $\mathrm{Na}$ Figura 1, abaixo, procuramos sintetizar essas relações.

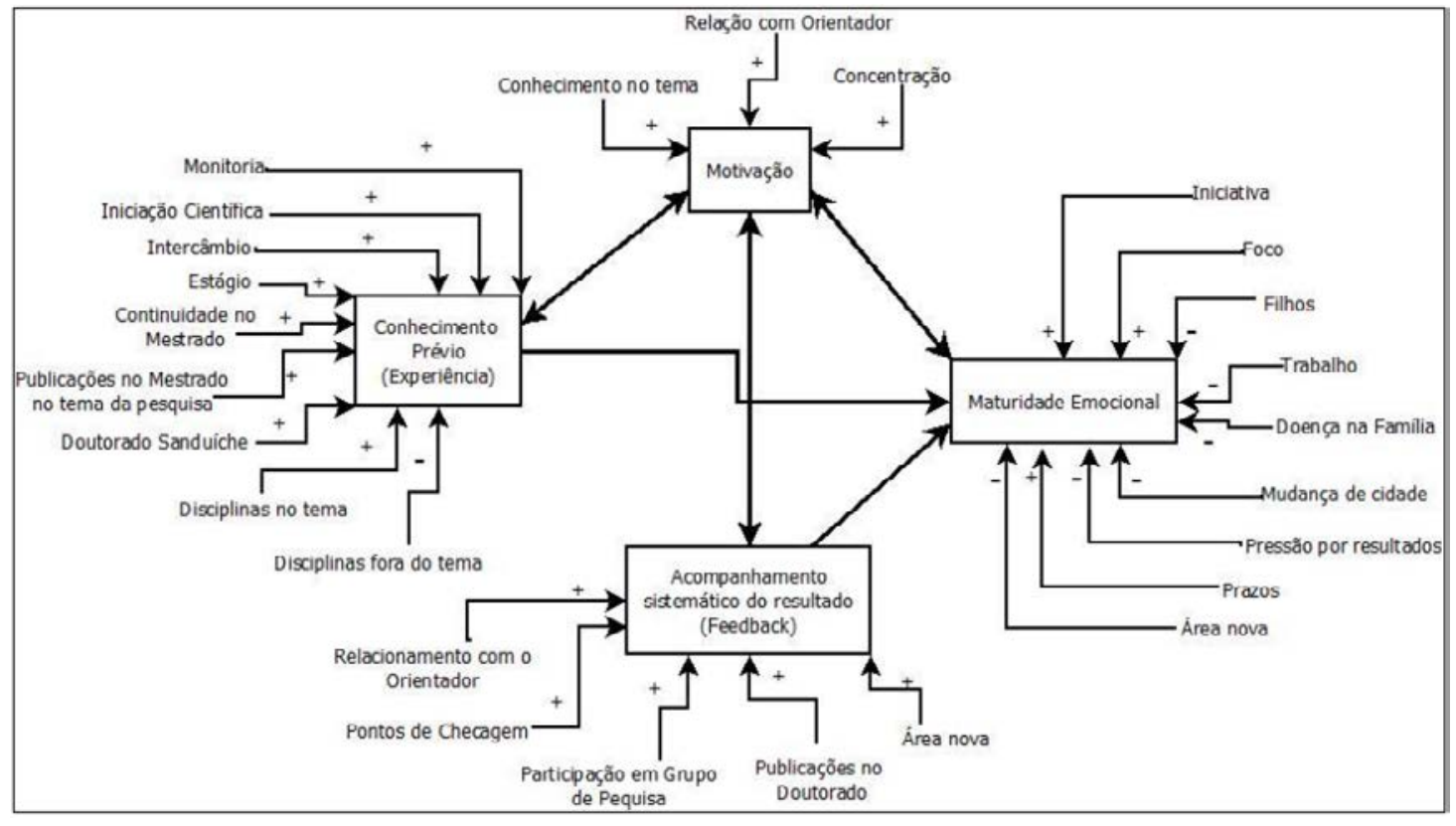

Figura 1. Núcleo de Fatores e seus Relacionamentos

\subsection{Usando Resultados para Melhorar a Evolução dos Problemas de Doutorado}

Nesta subseção discutimos como o resultado desta análise qualitativa pode ser utilizado para melhorar a forma como os problemas de doutorado em computação evoluem. Contudo, estas recomendações ainda não foram testadas na prática, assim elas somente definem estratégias derivadas dos resultados desta pesquisa.

O período de doutorado envolve, em média, quatro anos e existe uma grande possibilidade que algum tipo de fator externo venha acontecer e impactar na evolução do problema de pesquisa. Infelizmente, parte dos fatores externos não tem como ser 
evitados, mas recomenda-se atenção com aqueles possíveis de se mitigar. A motivação com relação a pesquisa e a maturidade emocional do aluno ajudam a superar os obstáculos. Em algumas situações, a ajuda de um e psicanalista pode ser útil.

O conhecimento prévio no tema da pesquisa é um fator de sucesso para o doutorado. A formação prévia é importante, ter feito uma graduação e um mestrado de forma dedicada ajudam a ter uma base sólida para uma evolução do problema de pesquisa. Apoio do orientador, co-orientador ou grupo de pesquisa é de grande valia para validação da pesquisa que está sendo realizada. As publicações realizadas e a participação em grupos de pesquisa facilitam a evolução do problema de pesquisa.

\section{CONCLUSÕES}

Neste artigo, apresentamos os principais resultados de uma pesquisa qualitativa básica sobre a evolução do problema de pesquisa no doutorado de no grupo LER, vinculado ao Programa de Pós-Graduação em Computação da UFPE.

Com os resultados obtidos neste trabalho, mostramos uma teoria que explica como ocorre a evolução de um problema de pesquisa e a complexa interação entre os fatores positivos e negativos que influenciam neste processo. Embora os resultados da pesquisa qualitativa apresentado neste artigo não podem ser generalizados, os princípios centrais da teoria e do método de pesquisa podem ajudar outros pesquisadores a reinterpretar a teoria em contextos específicos.

Como trabalho futuro, pretendemos replicar este estudo em outros grupos do programa de pós-graduação da UFPE para ampliar o entendimento sobre a evolução dos problemas de doutorado na área de Computação.

\section{Referências}

Duque, J. C., Brondani, J. T., Luna, S. P. L. Estresse e pós-graduação em medicina veterinária. RBPG, v.2, n. 3, p.134-148, 2005.

GEOCAPES. Ministério da Educação. Disponível em http://geocapes.capes.gov.br/geocapes2/ Acessado em 23 de Novembro de 2015.

Godoy, A., da Silva, E. E., Figueiredo, R. C. Efeitos do Estágio Docente na Formação do Pós-Graduando. Workshop de Educação em Informática (WEI), Natal-RN, 2011.

Goleman. D. Inteligência Emocional. A teoria revolucionária que redefine o que é ser inteligente. Ed. Objetiva. 1996.

Merriam, S. B. Qualitative research: a guide to design and implementation. 2009.

Neta, N. F. A.; García, E. G.; Gargallo, I. S. A inteligência emocional no âmbito acadêmico: uma aproximação teórica e empírica. Psicol. Argum. 2008.

Salvetti, M., Bueno, M.; Gastaldo , D., Kimura, A., Pimenta, C. Doutorado Sanduíche: Considerações para uma experiência de sucesso. Rev. Gaúcha Enferm., 2013.

Strauss, A., Corbin, J. M. Basics of Qualitative Research: Second Edition: Techniques and Procedures for Developing Grounded Theory. Sage Publications, 2007.

Stump, S., Knihs, E., Omar, N., Mustaro, P., Silveira, I. Discutindo a Construção do Pensamento em Pós-Graduandos. Workshop de Educação em Informática, 2011. 